\title{
MATÉRIA DE CAPA
}

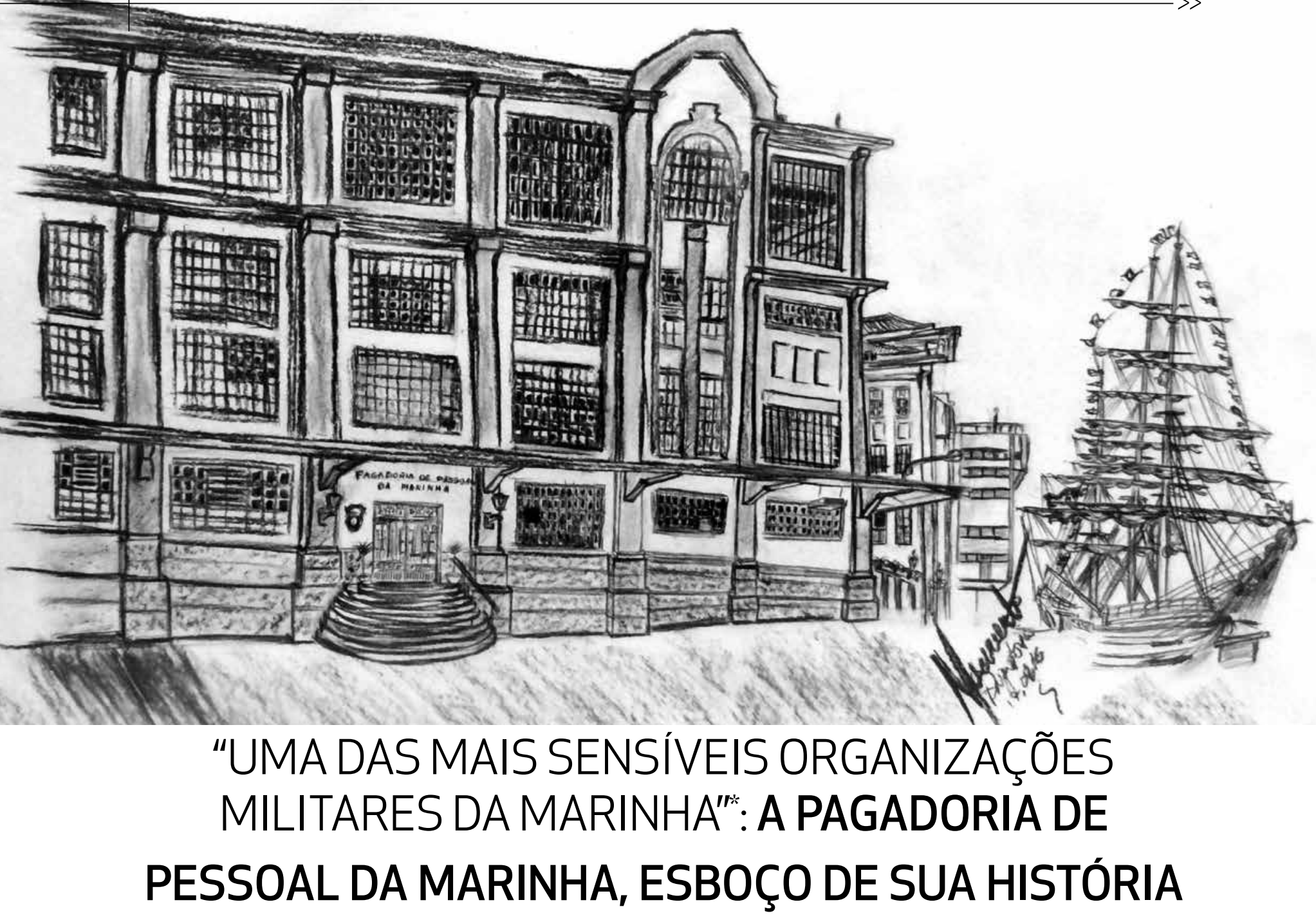

\begin{abstract}
A frase é de autoria do Contra-Almirante (IM) Paulo Mário Beserra de Araújo, então Diretor de Finanças da Marinha, publicada na Ordem de Serviço $n^{\circ}$ 005, de 19 de janeiro de 2000. Este artigo foi escrito mormente com base na documentação disponível nos diversos volumes que, em seu conjunto, constituem o Livro de Estabelecimento da Pagadoria de Pessoal da Marinha (PAPEM). Não pretende, de forma alguma, exaurir fatos e apresentar uma narrativa diacrônica desta Organização Militar, mas apenas destacar determinados elementos constitutivos de sua trajetória. Espera-se que possa instigar novas pesquisas acerca do tema.
\end{abstract}

\section{Marcello José Gomes Loureiro}

"Doutor em História e Civilização, pela École des Hautes Études en Sciences Sociales de Paris, e Doutor em História Social, pelo Programa de Pós-graduação em História Social da Universidade Federal do Rio de Janeiro (PPGHIS-UFRJ). Capitão de Corveta (IM). Encarregado da Divisão de Intendência da DPHDM. E-mail: marcello.loureiro@marinha.mil.br

“Mudar é preciso! Embora se possa claramente vislumbrar que haverá um aparente período de retrocesso; embora possam ocorrer obstáculos, julgados por alguns, apressadamente, intransponíveis, mudar é evoluir; mudar é preciso... desde que necessário. E o é".1

Ordem de Serviço $n^{\circ}$ 001, de 27 de março de 1997, do Diretor da
"Marinha sai na frente e paga atrasados semana que vem". Este foi o título da matéria publicada em 16 de maio de 2008, no jornal "O Dia", que elogiava a eficiência da Pagadoria de Pessoal da Marinha na execução de paga-

Pagadoria de Pessoal da Marinha, CMG(IM) Hamílcar Costa Júnior, elaborada por ocasião da ativação da PAPEM. 
mentos atrasados referentes ao acerto concedido a militares. Graças à elaboração de uma folha suplementar, à utilização de recursos próprios, e ao esforço desmedido da tripulação da PAPEM, a Marinha mostrava-se capaz de efetivar o adiantamento no menor tempo possível. ${ }^{2} \mathrm{O}$ episódio, de relevante repercussão, é exemplo que descortina a importância fulcral da PAPEM e de sua eficiência.

Ativada em 27 de março de 1997, os estudos para implantação de uma Pagadoria começaram com a devida anterioridade. Já em 1994, a reorganização dos processos administrativos agregados às atividades de pagamento de pessoal tivera início, motivada em grande medida, pelas "dificuldades [de a Diretoria de Finanças da Marinha] aprimorar o exercício de suas atribuições regulamentares", uma vez que costumava "dedicar a maior parte do tempo e recursos disponíveis para atender tarefas executivas pertinentes a gestorias, em especial a do pagamento de pessoal".3 Tempos depois, razões explicativas similares se confirmavam: "a execução das tarefas relacionadas com esses sistemas [de pagamento atinentes ao pessoal], por seu vulto e complexidade, impedia que a DFM exercesse, em sua plenitude, as atividades de planejamento e controle dos sistemas sob sua responsabilidade, o que conflitava com a Orientação Ministerial de que as DE [Diretorias Especializadas], somente em caráter excepcional e limitado, devem (sic) exercer atividades de execução".

Em 1996, o Ministro da Marinha, Almirante de Esquadra Mauro Cesar Rodrigues Pereira, pela Portaria $n^{\circ}$ 102/1996, instituía a Pagadoria de Pessoal da Marinha, "OM com autonomia administrativa". Buscava-se "a

2 Mensagem R-191700Z/MAI/2008, de SGM para PAPEM, com informação às OM subordinadas à SGM.

3 Ofício $n^{\circ}$ 2057/1994, da Diretoria de Finanças da Marinha à Secretaria-Geral da Marinha, de 27 de maio de 1994 (Assunto: Aprimoramento da Organização e Distribuição de atribuições na Área da DFM)

4 Ordem do dia n001, de 27 de março de 1997, da Secretaria-Geral da Marinha.

5 Memorando n004, da Secretaria-Geral da Marinha à Diretoria de Finanças da Marinha, de 19 de março de 1996 (Assunto: criação da Pagadoria de Pessoal da Marinha); e Portaria Ministerial nº 0102, de $1^{\circ}$ de março de 1996. descentralização administrativa na Marinha", para se "alcançar novo patamar de eficiência operacional [...] em área financeira específica". ${ }^{\circ}$

Para tanto, a DFM cederia parcela de seu pessoal, que constituiria o efetivo inicial da PAPEM, exceto seu Diretor. Ademais, o Departamento de Processamento de Dados da DFM tornar-se-ia um departamento operacional da nova OM, base de execução dos "grandes sistemas coorporativos da MB". Isso era relevante, para que não houvesse descontinuidade administrativa, nem sequer perda de conhecimento. Outra decisão central já se estabelecia: a PAPEM assumiria "somente funções de pagadoria, não se envolvendo nos aspectos legais do pagamento, [...] estudados e decididos por Órgãos de Competência Legal (OCL)".

Alguns meses mais tarde, todavia, a Portaria $n^{\circ}$ 102/1996 era revogada, sendo substituída pela de $n^{\circ} 65$, de 18 de fevereiro de 1997, data em que se comemora o aniversário da PAPEM.7 Em suma, esta portaria alterava a denominação do órgão pagador, de Pagadoria do Pessoal da Marinha, para Pagadoria de Pessoal, "por ter o propósito de sua missão se tornado mais abrangente: 'administrar os sistemas de pagamento do pessoal da Marinha, no país e no exterior".

Em fevereiro de 1997, a PAPEM já contava com uma proposta de regulamento. ${ }^{9}$ Nesse regulamento, em seu capítulo II, a Pagadoria figurava como um dos órgãos do sistema de controle interno da Marinha. Seu propósito mais amplo era "planejar, organizar, coordenar, prover recursos financeiros e controlar os sistemas de pagamento atinentes ao pessoal da MB". Dentre suas tarefas, deveria "administrar o sistema de pagamento de pessoal", atuar como "distribuidor do numerário necessário às Organizações Militares, destinado às gestorias conotadas a pessoal", além de "manter intercâmbio com entidades públicas ou privadas

6 Ordem de Serviço n 001, de 27 de março de 1997, do Diretor da Pagadoria de Pessoal da Marinha.

7 Mensagem R-311740Z/MAR/2000, de SDM para PAPEM.

8 Informativo $\mathrm{n}^{\circ}$ 01, de 25 de fevereiro de 1997, da Diretoria de Finanças da Marinha.

9 Ofício n 0405, do Diretor de Finanças da Marinha ao SecretárioGeral da Marinha, de 22 de fevereiro de 1997 (Assunto: Proposta de Regulamento da PAPEM). 
afins", representando a MB "em congressos e conferências relacionadas a assuntos de sua competência"10 Deveria dispor de quatro Oficiais Superiores, chefes de cada um de seus departamentos, e mais um Diretor. De início, apenas dois de seus departamentos funcionariam "normalmente": Informática e Processamento de Dados. Já em seu Regulamento aprovado, sublinhava-se que tanto o Diretor, como o Chefe do Departamento de Sistemas de Pagamento, deveria ser do Corpo de Intendentes de Marinha.

Após sua ativação, em 1997, era imperioso promover de fato seu estabelecimento. Primeiro, dar maior publicidade ao ato administrativo, a partir de notícias veiculadas em periódicos diversos;" baixar ordens diversas, que estipulavam desde orientações comportamentais comezinhas, a exemplo do relacionamento interpessoal, ou rotinas administrativas, até procedimentos operacionais complexos; ${ }^{12}$ obter publicações técnicas e normativas; e brasões, posters e trabalhos marinheiros para a decoração de suas dependências. ${ }^{13}$ Suas instalações seriam provisórias por alguns meses, e mesmo descontínuas, a exemplo do "protocolo" e do "pagamento no exterior", que funcionariam em espaços cedidos pelo Com1 ${ }^{\circ} \mathrm{DN}$, no pavimento térreo do Edifício Barão de Ladário..$^{14}$ Finalmente, movia-se do $6^{\circ}$ andar deste edifício para $04^{\circ}$ andar do edifício 23 do AMRJ, na llha das Cobras, em 18 de setembro de 1998. Em 2001, suas instalações físicas passavam por significativo processo de reformulação e modernização, a fim de se atingir mais segurança e conforto aos que nelas trabalhavam. ${ }^{15}$

10 Regulamento da Pagadoria do Pessoal da Marinha (Proposta), anexo ao Ofício $n^{\circ}$ 0405, do Diretor de Finanças da Marinha ao Secretário-Geral da Marinha, de 22 de fevereiro de 1997 (Assunto: Proposta de Regulamento da PAPEM).

11 Por exemplo: Caverna Mestra Boletim Noticioso da Reserva Naval e Pensionistas (Maio de 1997); Jornal da Praia, $n^{\circ} 659$, de 30 de maio de 1997; e BONO Especial n 134, de 25 de março de 1997.

12 Memorando $n^{\circ} 001$, do Diretor da Pagadoria de Pessoal da Marinha, de 12 de maio de 1997 (Assunto: Senso de Disciplina. Anexo: Relação de Ordens, Diretrizes e Recomendações".

13 BONO Geral n 114, de 14 de março de 1997; e BONO Geral n 110, de 11 de março de 1997

14 Informativo ${ }^{\circ}$ 02, de 25 de fevereiro de 1997, da Diretoria de Finanças da Marinha; e BONO Especial n 134, de 25 de março de 1997.

15 Ordem do Dia n 01, de 18 de fevereiro de 2001, da Pagadoria de Pessoal da Marinha (Quarto Aniversário da PAPEM).
Em seu conjunto, a criação da Pagadoria não se traduzia em mero ato formal. Com efeito, tratava-se de privilegiar a atividade de pagamento, ampliando recursos materiais e pessoais para sua consecução, a partir de critérios seguros de eficiência, acurácia e confiabilidade. A mudança, que para alguns talvez pudesse parecer impertinente, foi considerada, antes de tudo, necessária, como registrou o CMG(IM) Hamílcar Costa Júnior, primeiro diretor da Pagadoria, em sua Ordem de Serviço de assunção. ${ }^{16}$

Desnecessário ressaltar que o pagamento de pessoal se configura como uma das atividades mais nevrálgicas de qualquer organização. Traduz-se pela oportunidade em que a instituição reconhece, explicita e remunera o valor dos serviços prestados pelos seus componentes, permitindo que se consolidem vínculos de reciprocidade. De outra parte, é o momento em que militares e servidores viabilizam suas vidas, admitindo que sua profissão é capaz de lhes conferir identidade e inserção social. Na teoria clássica, Maquiavel, por exemplo, insistia que o pagamento era instrumento indispensável de motivação dos soldados. ${ }^{17}$

Atualmente, a atividade de pagamento se viabiliza por um sistema de alta complexidade, sem dúvida um "dos mais sensíveis e dinâmicos sistemas que compõem a estrutura contábil-financeira da Marinha, cujo alcance e efeito repercutem preponderantemente sobre o psicossocial de nossa instituição"18 Por isso, e em função da própria essência de sua atividade, "o trabalho na PAPEM requer planejamento objetivo e criterioso, execução precisa e dinâmica, e controle adequado e apurado, sem que possam ser evitadas, no entanto, situações eventuais e de emergência que exigem pronta iniciativa, dose substancial de criatividade e extrema flexibilidade de ação"19 Como anotou certa vez o então CMG(IM)

16 Conforme epígrafe citada no início deste texto.

17 MAQUIAVEL, Nicolau. A arte da guerra. Tradução e notas de Eugênio de Morais. Porto Alegre: L\&PM, p. 200.

18 Ordem de Serviço $\mathrm{n}^{\circ}$ 008, de 11 de janeiro de 2002, do Diretor da Pagadoria de Pessoal da Marinha, CMG(IM) Edésio Teixeira Lima Júnior.

19 Ordem de Serviço $n^{\circ}$ 15, de 30 de janeiro de 2004, do Diretor de Finanças da Marinha, Contra-Almirante(IM) Luiz Antônio da Silva 
Alvarez, "embora exercendo uma atividade tipicamente de apoio logístico, o serviço de pagamento de pessoal se reveste de características que exigem alta capacidade operacional para dar cumprimento de suas tarefas num ambiente automatizado e dinâmico, onde o profissionalismo é imperioso".20 Não por outra razão, um de seus diretores, o então CMG(IM) Sérgio Luiz de Andrade, registrou em sua assunção que considerava "esta fase de minha carreira como um novo desafio a ser vencido".21

Os números são realmente impressionantes: já no ano de 2010, a PAPEM operacionalizava mais de 500.000 alterações mensais de pagamento, atendendo a cerca de 200.000 pessoas, em que se incluíam militares, servidores civis, ativos, inativos, ex-combatentes e pensionistas.22 Em 2014, a PAPEM controlava 350.000 contratos de empréstimos consignados em folha de pagamento, bem como o controle e repasse de crédito a 54 bancos ou entidades financeiras, e a 270 entidades consignatárias não financeiras. ${ }^{23}$

Ao longo de sua história, a PAPEM experimentou frequentemente momentos desafiantes, como por exemplo, o apoio fundamental prestado à Força Aérea Brasileira, por ocasião de um incêndio no Aeroporto Santos

\section{Lima.}

20 Ordem de Serviço n 005, de 19 de janeiro de 2000, da Pagadoria de Pessoal da Marinha.

21 Ordem de Serviço $n^{\circ} 23$, de 31 de janeiro de 2005, do Diretor da Pagadoria de Pessoal da Marinha, CMG(IM) Sérgio Luiz de Andrade.

22 Ordem do Dia $n^{\circ}$ 01, de 18 de fevereiro de 2010, do Diretor da Pagadoria de Pessoal da Marinha, CMG(IM) Paulo Sergio Pagliusi.

23 Ordem de Serviço $n^{\circ}$ 14, de 22 de janeiro de 2014, do Diretor da Pagadoria de Pessoal da Marinha, CMG(IM) Cláudio de Carvalho Mattos.
Dumont, que acabou por interromper as atividades do Centro de Computação da Aeronáutica (CCA/RJ), em fevereiro de 1998.24 Do mesmo modo, vale salientar a implantação da nova estrutura remuneratória dos militares, em 2001. 25

0 mais recente projeto da PAPEM parece ser a modernização do SISPAG, cuja publicação do edital de licitação para primeira fase de execução remonta ao ano de 2008. ${ }^{26}$ Projeto de suma importância para a Marinha, que conta com a gerência técnica do CASNAV, o SISPAG 2 assegura a ampliação da qualidade dos processos de operacionalização do pagamento a refinado grau de excelência, com nova linguagem tecnológica, funcionalidades, ambiente virtual moderno, eficiência do controle interno, redução do risco de fraudes e erros e, portanto, mais segurança e melhor confiabilidade. Em janeiro de 2014, foi realizada a cerimônia de entrega do SISPAG 2, nas dependências da PAPEM. Nesse contexto, em que a Pagadoria se encontra em perfeito diálogo com o que há de melhor na ciência e tecnologia da informação, vale terminar lembrando uma frase proferida pelo então CMG(IM) Hamílcar, primeiro diretor da PAPEM, na alocução realizada na cerimônia de ativação da $\mathrm{Pa}$ gadoria: "O compromisso com o futuro está, portanto, assumido!"27

24 Mensagem P-161501Z/FEV/1998, de DFM para SGM, com informação para GCM e PAPEM

25 Ordem de Serviço $\mathrm{n}^{\circ}$ 007, de 11 de janeiro de 2002, do Diretor da Pagadoria de Pessoal da Marinha, CMG(IM) Carlos Henrique Gomes.

26 Cf. Jornal Valor Econômico, de 3 de março de 2008, Ano 09, n² 2208.

27 Ordem de Serviço $n^{\circ} 001$, de 27 de março de 1997, do Diretor da Pagadoria de Pessoal da Marinha.

\section{VISITE NOSSO SITE}

www.mar.mil.br/papem/ 